REVISTA DE DERECHO UNED, NÚM. 12, 2013

\title{
EL HUMANISMO CONTEMPORÁNEO COMO FUENTE Y FUNDAMENTO DE LOS DERECHOS FUNDAMENTALES
}

\author{
CONTEMPORARY HUMANISM AS SOURCE AND \\ FOUNDATIONS OF FUNDAMENTALS RIGHTS
}

\author{
Cayetano NúÑEz Rivero \\ UNED \\ LeONOR ANTONio Aular Viamonte \\ UNEG
}

Resumen: El Humanismo representa una corriente que está llamada a perdurar como basamento y orientación de las diversas formas del ser y el quehacer humano. Esa permanencia requiere una reflexión, una crítica y una renovación constante de sus principios e ideales de cara a su realidad histórica. Los cambios que se han suscitado y se siguen produciendo en el mundo de hoy, exigen un Humanismo que esté acorde con esa dinámica en la cual los Derechos Fundamentales constituyen una de sus expresiones más representativas y requeridas de un sólido basamento que reafirme la pertinencia e importancia que tienen estos derechos para que se pueda lograr una humanización permanente. En este artículo se plasma un conjunto de planteamientos e ideas dirigidos a argumentar las posibilidades de un Humanismo Contemporáneo como fuente y fundamento de los Derechos Fundamentales.

Descriptores: Humanismo, Derechos Fundamentales, Derechos Humanos, Anti-Humanismo, Anti-Modernismo, Humanismo Contemporáneo. 
Abstract: The Humanism represents a current calling to survive as a basement and orientation of being and work human numbers of ways. That permanency demand a reflection, a critic and constant renewal about his principles and ideals face to his history reality. The changes that have occurred and still being produced in the world of our days, demand an Humanism that is in accord with that momentum on which Fundamentals Rights constitute most representative expressions and demanded theoretical base that reaffirms the relevance and importance that these rights have could achieve a permanent humanization. En this article is embodied a joint development and ideas for giving the advantages the possibilities of a Contemporary Humanism as source and foundations of Fundamental Rights.

Key words: Humanism, Fundamentals Rights, Antihumanism, Antimodernism, Contemporary Humanism.

Recepción original: 12/06/2013

Aceptación original: 18/06/2013

Sumario: I. Las fuentes primarias del Humanismo. II. El pensamiento «anti-humanista» y «anti-moderno» como síntoma de la necesidad de reconfigurar un Humanismo Contemporáneo como basamento de los Derechos Fundamentales. III. Los aportes y las críticas para las propuestas del Humanismo Contemporáneo. IV. Reflexiones finales.

\section{LAS FUENTES PRIMARIAS DEL HUMANISMO}

El punto de partida del Humanismo se encuentra expresado en una concepción filosófica en la cual se enfatiza la dignidad y el valor de las personas, considerando como uno de sus principios básicos que son seres racionales poseedores en sí mismas de la capacidad para hallar la verdad y practicar el bien.

Como una concepción filosófica con implicaciones de carácter jurídico, el Humanismo se ha alimentado de diversas fuentes que indican las distintas formas con las cuales ha sido concebido a través de la historia. Dichas fuentes las registra González (2000) en diferentes etapas: la clásica, la renacentista y la ilustrada. Se puede afirmar que en estas etapas se encuentran las fuentes originarias de esta corriente filosófica.

En la primera etapa, ubicada en la Grecia Clásica, se destaca Sócrates como uno de los representantes más importantes y cuyo 
logro principal estuvo centrado en interesar a las generaciones de su época en superar el egocentrismo y el beneficio propio, a través de la satisfacción de sus necesidades superficiales, e interesarse por el conocimiento y su desarrollo como individuo y ciudadano.

El Humanismo Socrático tiene como uno de sus puntos de partida, la creencia en una comprensión objetiva de los conceptos de justicia, amor y virtud y el conocimiento de uno mismo. En ese sentido, Alegre (2004) destaca un argumento ético en el cual se plantea que «todo vicio es el resultado de la ignorancia y que ninguna persona desea el mal; a su vez, la virtud es conocimiento y aquellos que conocen el bien, actuarán de manera justa» (p. 29).

Ese argumento ético tiene una importante repercusión en la concepción del hombre en el mundo occidental, concepción que aún se encuentra presente como esencia fundamental de la visión humanista en la actualidad y como eje transversal de toda concepción relacionada con la realidad humana, sea esta pedagógica, social o jurídica.

En el Humanismo de Sócrates es importante destacar, junto con la Ética, a la Lógica como componente enriquecedor de sus argumentos fundamentales. Su planteamiento se realiza en los términos de una discusión racional para la búsqueda de definiciones generales, disensos y acuerdos, propuesta que se encuentra plenamente expresada en los Diálogos Socráticos, obra inmortal de uno de sus más importantes discípulos: Platón ${ }^{1}$.

Por otro lado, este énfasis del diálogo y la discusión racional como elemento clave para alcanzar el conocimiento, representa otro de los aspectos fundamentales que caracterizan al Humanismo Socrático, enfatizando la apertura, la discusión y el debate como elementos claves para lograr la construcción efectiva de los conocimientos.

La lógica socrática, que se ubicaría en los planos de la intersubjetividad, propone un método dirigido a favorecer la producción del conocimiento desde la interacción entre discípulo y maestro. En dicha interacción se le propone al discípulo establecer un encuentro consigo mismo en la búsqueda y el alcance del saber.

Las fuentes primarias del Humanismo en el Renacimiento surgen como consecuencia de la evolución social e ideológica de Europa, fundamentalmente al chocar con los principios propugnados por las reformas luteranas y calvinistas y la contrarreforma católica. Chastel y Klein (2002) afirman que estos hechos llevan a una concepción del

1 Los aportes principales a la Lógica por parte de Sócrates y Platón se encuentran en la semiótica y en la retórica. 
hombre como ser "universal e individualista que se distingue por sus talentos y su vitalidad, así como por una gran curiosidad, que lo lleva no sólo en busca de nuevos continentes, sino también de la verdad científica» (p. 32).

Este planteamiento indica una visión antropocentrista, donde se asume que el hombre posee todo la capacidad intelectual y vital para llevar a cabo las acciones que le conduzcan a su evolución permanente en la búsqueda de la verdad y el desarrollo de su creatividad, como aspectos caracterizadores y claramente distintivos de la condición humana.

Esta noción constituye una de las fuentes principales de lo que representa el Humanismo como corriente y pensamiento propio de la cultura occidental y como fundamento de las propuestas que se hacen en el campo de la pedagogía y el derecho, entre otros y desde la cual se plantea toda superación del pensamiento dogmático-religioso que prevaleció en el oscurantismo medieval para dar paso a la creatividad, al arte y al pensamiento científico.

Es importante destacar que es precisamente en la etapa renacentista cuando se da apertura al uso del términos «humanista» para referirse a la liberación de la ignorancia y el dogmatismo de «la edad de las tinieblas» e ir en búsqueda de la verdad, la belleza, la libertad y la dignidad humana, propugnando una formación íntegra del hombre en todos los aspectos fundada en las fuentes clásicas grecolatinas para hacer frente al teocentrismo de la época medieval, a través de una vía hacia el antropocentrismo que llega a expresarse a través de los llamados studia humanitatis, que consistían en estudios de las fuentes grecolatinas como fuentes para la formación integral del hombre.

El propósito expresado en el Humanismo del Renacimiento, como corriente antropocéntrica dirigida a hacer frente al teocentrismo medieval, a través de los studia humanitatis, podría llevar a pensar que desde la formulación de este propósito no se generan elementos para la constitución del Humanismo como fundamento y fuente de los derechos humanos.

Sin embargo, es importante hacer referencia a lo que afirma Bullock (2000) cuando afirma que entre los aspectos que caracterizan al Humanismo de la Etapa Renacentista, se encuentran los siguientes:

- El antropocentrismo o consideración de que todo gira en torno al hombre, frente al teocentrismo medieval.

- Se restaura la fe en el hombre porque posee valores importantes que no conviene despreciar. 
- La razón humana adquiere valor, aspecto que se expresa no sólo en los escritos filosóficos y pedagógicos, sino también en la obra de arte, especialmente en la pintura.

- El deseo de la unidad política y religiosa de Europa bajo un sólo poder político y un solo poder religioso separado del mismo: se reconoce la necesidad de separar moral y política, autoridad eterna y temporal.

- El optimismo frente al pesimismo medieval. Existe fe en el hombre: la idea de que merece la pena pelear por la fama y la gloria en este mundo incita a realizar grandes hazañas y emular las del pasado. La fe se desplaza de Dios al hombre.

- El contraste de opiniones frente al argumento de la autoridad medieval: la imprenta multiplica los puntos de vista y las discusiones, enriqueciendo el debate intelectual y la comunicación de las ideas. Se ponen de moda los géneros del diálogo y la epístola, todo lo que suponga comunicación de ideas.

El énfasis en los estudios literarios, el arte de la retórica y la elocuencia no pueden ocultar en modo alguno las fuentes y fundamentos de un antropocentrismo que está presente en el pensamiento humanista del Renacimiento. Estas van constituir el punto de partida de lo que será el Humanismo de la Ilustración y la marca distintiva del Humanismo como corriente universal.

El llamado Humanismo Ilustrado indudablemente tiene una deuda invalorable con el Humanismo del Renacimiento, pero, a la vez, constituye un paso de avance en lo que representan las fuentes primarias del Humanismo como corriente del pensamiento occidental. Respecto a ello, Choza (2009) afirma que «donde el Renacimiento no percibía posibilidad de síntesis, ni ideal formulable, ni válido para todos, la Ilustración encuentra uno que, al menos como procedimiento, proporciona la unidad perdida de la cristiandad, a saber, la racionalidad científica» (p. 175).

En el Humanismo Ilustrado o el Humanismo de la etapa de la Ilustración se introduce un componente fundamental como lo es la razón, a partir del «cogito ergo sum» cartesiano ${ }^{2}$. A través de ese componente se logra canalizar la búsqueda del saber que se propone desde diversas instancias y ámbitos de la realidad humana y que constituye basamento y fuente de todo obrar moral y cívico dirigido

2 El planteamiento cartesiano representa uno de los esfuerzos que se han realizado para reafirmar la conciencia reflexiva del sujeto como basamento para la comprensión de su realidad. 
a superar toda forma de superstición en el hombre y su miseria moral y espiritual (Choza, 2009).

Así mismo, tal como lo señala Orejudo (2006), «se produce una separación radical entre el hombre y la naturaleza que dará lugar a la aparición del sujeto como nueva figura de la modernidad» (p. 44). Esto logra configurar un pensamiento donde la figura del hombre como ente racional, creativo y en proceso permanente de evolución, se constituye en el eje y centro de la historia, de la sociedad, sin depender de los dogmas o imposiciones de las creencias religiosas.

Respecto a las ideas que se hacen presentes en la Ilustración como una de las fuentes primigenias del Humanismo, Fromm (1985) ha señalado lo siguiente:

Las ideas de la Ilustración enseñaron al hombre que puede confiar en su propia razón como guía para establecer normas éticas válidas y que puede depender de sí mismo sin necesitar de la revelación ni de la autoridad de la Iglesia para saber lo que es buen o y malo (p. 17).

Los aportes de esta etapa, vertidos en la incorporación de la razón científica como eje que sustituye los imperativos religiosos y acompaña el comportamiento moral, propugnan una liberación del hombre del dogmatismo e incentivan la autonomía humana, donde se propugna el «atrévete a saber» y el «confía en tu conocimiento» como incentivos para los esfuerzos y los logros del hombre en todos los campos del saber y de la creación.

Tal aporte lleva a Choza (2009) a afirmar que el Humanismo Ilustrado llega a tener "la universalidad que tenía la romana, la urgencia mesiánica de cumplimiento que tiene la cristiana y el enfoque hacia la soberanía singular que tenía la renacentista» (p. 175).

Disponer de estas ventajas se ve complementado con la exclusión claramente del elemento religioso, por lo que su orientación se dirige hacia otros rumbos. Estos, señala Choza, están en función «del orden político según programas que tenían precisamente esas características de contenido, amplitud y fuerza y que conocemos con el nombre de ideologías políticas» (p. 176).

Con la Ilustración se configura la presencia de la razón humana como eje central del conocimiento, basamento determinante de una ética y como sustento de ideas políticas que sustituyen las propuestas que provienen del dogmatismo, partiendo del ser humano como ente protagónico en los procesos dirigidos a la construcción de un orden social, justo, equilibrado y de bienestar en el propio contexto de la realidad terrenal. 
Las ideas presentes en la Ilustración configuran, conjuntamente con las tesis socráticas y el pensamiento del Renacimiento, los ejes desde los cuales se configuran las fuentes primarias del Humanismo que, a su vez, representarán los basamentos necesarios para la estructuración de los fundamentos Humanistas de los Derechos Fundamentales. Estas fuentes se hacen presentes a través de una serie de aportes que se pueden resumir en los aspectos que se señalan a continuación:

- Fomento de la creencia en una comprensión objetiva de los conceptos de justicia, amor y virtud y el «conócete a ti mismo».

- Formulación y promoción de una lógica subjetiva dirigida facilitar la discusión racional para la búsqueda de definiciones generales, disensos y acuerdos.

- Desarrollo del antropocentrismo o consideración de que todo gira en torno al hombre, frente al teocentrismo medieval.

- Separación del poder político y el solo poder religioso que implica la necesidad de separar moral y política, autoridad eterna y temporal.

- Enaltecimiento de la razón científica para canalizar la búsqueda del saber y constituirse en basamento de toda acción moral.

- Sustitución de los imperativos y dogmatismos religiosos y promoción la libertad y la autonomía humana.

- Desarrollo de las ideas y las ideologías políticas como sustitutas del dogmatismo religiosos y como propuestas donde se promueve al ser humano como protagonista y constructor de un destino orientado hacia perfectibilidad permanente y el desarrollo de un orden social, justo, equilibrado y de bienestar en la tierra.

II. EL PENSAMIENTO «ANTI-HUMANISTA» Y «ANTIMODERNO» COMO SÍNTOMA DE LA NECESIDAD DE RECONFIGURAR UN HUMANISMO CONTEMPORÁNEO COMO BASAMENTO DE LOS DERECHOS FUNDAMENTALES

Es importante recordar que el legado fundamental del siglo XIX fue la razón científica, conjuntamente con el ideal del hombre como sujeto protagónico de su historia. Sin embargo, los hechos históricos del siglo XX llegan a constituirse en un cuestionamiento severo a este legado. Al respecto, Estrada (2009) señala lo siguiente:

Sin embargo, el siglo XX, que inicialmente continuó esta tendencia en la segunda revolución industrial, se vio afectado por una serie 
de acontecimientos que obligaron a un replanteamiento del papel del conocimiento científico. Por un lado, están los desastres de las dos guerras mundiales simbolizados por Hiroshima y Auschwitz, que planearon el papel de la ciencia en la construcción de una sociedad emancipada. La razón científico técnica fue un poderoso instrumento de progreso, pero también de amenaza potencial para el ser humano (p. 62).

La contundencia de este y otros hechos ponen en entredicho las verdaderas posibilidades y las alternativas de la razón y de la subjetividad humanas como vías para la reafirmación del desarrollo de la humanidad y la evolución permanente hacia una mejor sociedad. Este cuestionamiento de la razón se profundiza en pensamientos e ideas no solamente críticas con relación a la racionalidad y al Humanismo, sino también en planteamientos anti-racionalistas y antihumanistas.

Entre esos planteamientos, Fernández y Orejudo (2012) señalan el de Hanna Arendt, cuyo pensamiento anti-moderno, de acuerdo con estos autores, es «una respuesta al fracaso de la Ilustración, el cual pudo vivir y experimentar la autora de manera íntima y personal a través de la política de exclusión de los judíos de la cultura y de la sociedad alemana con el auge del nazismo» (p. 106).

El desarrollo de esta idea anti-moderna y anti-racionalista se puede calificar como dentro de las orientaciones de un verdadero antihumanismo, donde, tal como lo afirma Orejudo (2006), se propugna la superación del Humanismo, como «como un paso necesario para superar los males de la modernidad, como los colonialismos y los totalitarismos» (p. 45).

Al identificar al Humanismo con la racionalidad científica y el modernismo, Arendt considera que el mismo ha representado la causa fundamental generadora de las distorsiones antes referidas, por lo que su pensamiento llega a configurar un marcado anti-humanismo que se justifica en la idea que las conflagraciones mundiales, el holocausto, las diferentes formas totalitarias (comunismo y fascismo), no son más que consecuencias del mismo.

Fernández y Orejudo (2012) confirman lo anterior, cuando destacan cuatro perspectivas desde las cuales se ubica el anti-modernismo y anti-humanismo de Arendt. Dichas perspectivas son analizadas a continuación:

La primera se refiere a lo que los autores señalan como un intento de esta autora por volver a los antiguos "por un intento de recuperar a través de las categorías aristotélicas el ideal de la vida 
política griega, y concretamente, el sentido de la acción humana como praxis» (p. 107). Esta perspectiva anti-modernista pudiera entenderse como una proposición para el rescate de la racionalidad humana griega como verdadera alternativa a la razón tecnológica, fundamento esencial de la modernidad.

La segunda perspectiva anti-humanista y anti-modernista presente en Arendt la localizan Fernández y Orejudo (2012) en las críticas realizadas por la autora a los totalitarismos, catalogándolos como «como fenómenos históricos esenciales de la modernidad que carecen de antecedentes en la antigüedad»(p. 107). La identificación de los totalitarismos con la modernidad constituye un argumento desde el cual se plantea que existe una intrínseca relación entre el humanismo moderno y la racionalidad tecnológica de occidente y los totalitarismos, cuyas expresiones más conocidas e impactantes en el siglo XX se encuentran representadas en el nazismo alemán y el comunismo-estalinismo soviético.

$\mathrm{Al}$ respecto, es pertinente hacer referencia a lo que afirma Estrada (2009) cuando afirma que "el fascismo y el estalinismo, prototipos de los totalitarismos del siglo XX, se conciben como corrientes sociopolíticas que se apoyan en la revolución industrial y que hacen del pensamiento científico técnico la base de su dominio social» (p. 62).

Los planteamientos señalados por Arendt indican que los regímenes totalitarios y las más acabadas expresiones de lo que se denominaría imperialismo, no constituyen problemas y realidades que se limitan a un determinado ámbito cultural, sino que son la expresión de las consecuencias de la modernidad y de la razón científico-tecnológica.

La tercera perspectiva que destacan Orejudo y Fernández en lo que ellos denominan postura anti-moderna de Hannah Arendt, está tomada de Edmund Burke ${ }^{3}$. Según los autores dicha postura se manifiesta en un aborto rechazo a la noción de derechos humanos y «está relacionada con la crítica que desarrolla Hannah Arendt, inspirándose en Burke, contra el carácter demasiado `abstracto` de los derechos humanos» (ibídem).

Desde este planteamiento, el planteamiento anti-humanista se hace extensivo a los derechos humanos, aduciendo su carácter abstracto y, por lo tanto, su inconsistencia, que lleva a la conformación

3 EDMUND BURKE tiene amplia resonancia en la historia, entre cosas, por su crítica severa a los principios de la Revolución Francesa y a los Derechos Humanos, al considerar a estos últimos como de «grave peligro» para los pueblos dado su carácter abstracto. 
de un hombre que termina siendo «una entidad abstracta sin conexión alguna con el orden político y social que le rodea, y por esta razón, un ser desposeído y sin mundo» (Fernández y Orejudo, p. 108).

En la cuarta perspectiva de su anti-modernismo, Arendt, de acuerdo con el análisis de Fernández y Orejudo (2012), se ubica dentro del existencialismo político, donde se enfatiza como una práctica «no solamente irreductible a la fuerzas económicas, sino también como algo no sometido a ninguna clase de restricciones normativas o instrumentales» (p. 111).

En atención a lo que se señala anteriormente, el argumento político prevalece a toda normativa, donde se incluye la que se refiere a los derechos humanos, y a ese respecto se le da un mayor fundamentación política a la libertad, como alternativa de mayor posibilidad para que la misma alcance su grado de realización en la práctica con respecto a una propuesta de carácter meramente normativo y abstracto.

En opinión del autor, las cuatro perspectivas señaladas por los autores con relación a los planteamientos de Arendt, representan argumentos que deben mover hacia una reflexión crítica con relación a lo que ha representado el Humanismo y la necesidad de incorporar elementos de innovación que favorezcan el perfeccionamiento de sus ideas principales y reforzar sus tesis fundamentales.

En ese sentido, al hablarse en la perspectiva de un retorno a los ideales del pensamiento clásico en lo que señala Arendt, se estaría precisamente a un retorno a los ideales que precisamente dieron inicio y fundamento al pensamiento y al ideal del Humanismo y que tiene en Sócrates a uno de sus principales representantes y desde cuyos ideales parten las diferentes corrientes que de una manera o de otra reafirman al ser humano y sus posibilidades en el mundo ${ }^{4}$.

Así mismo, cuando la autora analizada afirma que los totalitarismos son una expresión de la modernidad, es importante tomar su planteamiento como un argumento para la reflexión acerca de la forma como se han utilizado los logros de la modernidad para un verdadero desarrollo humano y no obviar que en materia de defensa de los derechos humanos. Igualmente, no se debe olvidar que los

\footnotetext{
4 ARENDT hace referencia al ideal aristotélico como la fuente hacia la cual se ha de retornar, pero no se debe olvidar la influencia del pensamiento socrático en Platón y Aristóteles.
} 
fenómenos del fascismo y el comunismo soviético, entre remiten determinados contextos históricos y socio-culturales ${ }^{5}$

También se debe señalar que la «abstracción» de los derechos humanos debe ser objeto también de reflexión y análisis, pero no para su rechazo o negación, sino para plantear nuevas formas y estrategias que conduzcan a su consecución en realidades concretas y contribuir con ello a una verdadera concreción de los mismos dentro de los parámetros y normas que se desprenden de sus principios.

Así mismo, la concreción de los derechos fundamentales debe estar relacionada con una praxis política que se guíe por esos principios y, a la vez, procure el fortalecimiento de las instituciones y organizaciones que en los diferentes países se encuentran abocadas a la protección y defensa de los derechos humanos, a través de instrumentos y recursos que provean mayor efectividad en las acciones.

En ese sentido, hablar de un "anti-humanismo» o de un "antimodernismo», implica, en opinión del autor, plantear una profunda reflexión crítica sobre el Humanismo como corriente y como propuesta fundamental de una teoría y una praxis. Dicha reflexión apuntaría, si se toman debidamente en cuenta sus argumentaciones, el punto de inflexión que abre las posibilidades de enriquecimiento y renovación de los planteamientos originarios relacionados con el ideal humanista.

\section{LOS APORTES Y LAS CRÍTICAS PARA LAS PROPUESTAS DEL HUMANISMO CONTEMPORÁNEO}

En el contexto de lo que se denominarían las propuestas actuales, en este trabajo se señalan las que se configuran durante el siglo XX y que han constituido planteamientos renovadores que muestran la evolución de las ideas y argumentos de esta corriente como planteamientos y argumentos posibles con relación a los Derechos Fundamentales.

Los aportes que se hacen en el transcurso del siglo XX vienen a constituir respuestas dirigidas, por un lado, a plantear críticas de fondo respecto a los planteamientos fundamentales relacionados con el Humanismo, pero por el otro, a reafirmar la importancia de la razón humana como posibilidad del hombre, a pesar de los estragos

5 El fascismo alemán, el comunismo soviético y todas las cruentas consecuencias de sus políticas y acciones fueron fenómenos que se dieron históricamente en contextos específicos representados en culturas alemana y rusa. 
de la modernidad, que se han expresado, entre otros hechos, en un desarrollo depredador no sostenible, las dos guerras mundiales, las políticas colonialistas, las guerras regionales (Sudeste Asiático, Medio Oriente) y el totalitarismo en su distintas formas.

Se pueden destacar diversos aportes que pueden llegar a configurar componentes de un basamento contemporáneo del Humanismo con relación a los Derechos Fundamentales. A ese respecto, se pueden destacar los planteamientos realizados en el Existencialismo representado en Jean Paul Sartre; los de la Escuela de Frankfurt, en la figura de Herbert Marcuse y los surgidos del Psicoanálisis Social donde se destaca Erich Fromm como uno de sus principales promotores.

El Existencialismo de Sartre constituye una de las fuentes revitalizadoras del Humanismo contemporáneo y ello viene dado por el hecho que en su propuesta filosófica se reafirma el carácter esencial de la relación entre el hombre y la libertad. En su obra El Existencialismo es un Humanismo, Sartre (2006) hace la siguiente afirmación: «Estamos solos, sin excusas. Es lo que expresaré diciendo que estamos condenados a ser libres» (p. 37).

Esta reflexión constituye lo que se puede denominar un soporte esencial para confirmar la pertinencia del ideal humanista como fuente y basamento de los principios que deben guiar la praxis humana en el mundo, pues hace recaer en el hombre y solo en él, la responsabilidad de sus actos y las posibilidades de su porvenir en términos humano-terrenales y no teológicos.

En ese sentido, el aporte que se hace en el Humanismo Existencialista de Sartre se encuentra expresado en una noción acerca del hombre donde es sujeto de la acción y en un proceso constante de realización en el cual su existencia es concebida en términos de conciencia y de permanente e inacabada realización, lo que lo diferencia de la cosa.

Igualmente, el Humanismo que se propone desde la perspectiva del Existencialismo sartreano es contrario a toda noción cerrada, en el sentido de que no plantea al hombre como fin, sino como constantemente fuera de sí mismo y en permanente proceso de concepción en virtud de su existencia, «el hombre no es otra cosa que lo que él se hace» (Sartre, 2006, p. 28), viene a considerarse un principio primigenio de este Humanismo desde el cual se asume que el hombre no es más que lo que el mismo se hace en las relaciones que establece con el mundo que le rodea y las acciones que realiza en él. 
Dichas acciones conforman su existencia y preceden su esencia, por lo que en este Humanismo, la acción del hombre en el mundo, el permanentemente proyectarse y el rebasarse, vienen a representar las formas como llega a trascender en términos totalmente desligados de toda noción religiosa y vinculados a una praxis en el mundo en la cual se crea y se inventa ad infinitum.

Los nuevos aportes que se hacen al Humanismo a través de la Escuela de Franfurkt en la figura de Herbert Marcuse, se encuentran claramente expresados en una crítica severa que hace el autor a la sociedad y al sistema económico industrial como opresores de la libertad humana y la necesidad de producir cambios en profundidad en ellos, como condición indispensable para que el ser humano alcance grados plenos de libertad y el desarrollo de su condición humana.

En una de sus obras más importantes, El Hombre Unidimensional, Marcuse (1993) resalta que en el marco de la sociedad capitalista avanzada, el sujeto es víctima de su propia imposibilidad y de la opresión continua que se genera desde dicha sociedad, donde se han alcanzado estados de bienestar que se expresan en un elevado nivel de vida de los trabajadores, en detrimento de su libertad. Ante ello propone lo siguiente:

No es simplemente una sociedad fundada sobre otras relaciones de producción (aunque semejante transformación de la base permanezca como una condición necesaria de la liberación): se trata de una sociedad en la cual las nuevas relaciones de producción y la productividad desarrollada a partir de las mismas, sean organizadas por los hombres cuyas necesidades y metas instintivas sean la «negación determinada» de los que reinan en la sociedad represiva (p. 9).

El Humanismo que se plantea en Marcuse se relaciona con un profundo cambio social, donde las relaciones de producción y la capacidad productiva estén en manos de los propios hombres y no de los intereses y requerimientos de las corporaciones y del poder omnímodo del Estado como entidades supresoras del ser humano, donde:

La diferencia cualitativa se manifestaría en la trascendencia política de la energía erótica, y la forma social de esta trascendencia sería la cooperación y la solidaridad en un mundo social y natural que, al destruir la dominación y la agresión represiva, se colocaría bajo el principio de la realidad de la paz (p.10).

Lo argumentado por Marcuse coloca sus planteamientos en el marco de un Humanismo con un claro componente social, cultural y psicoanalítico, que permite evidenciar la influencia que ha tenido de 
autores como Hegel, Marx y Freud. A ese respecto, su propuesta humanista se enmarca dentro de un proceso revolucionario que abarca no sólo los aspectos económicos, sino también los de orden cultural, social, políticos, psicológicos y erótico-sexuales. Es decir un proceso de alta complejidad, de largo aliento y de posibilidades duras, ante el cual es necesario estar claramente persuadidos y conscientes.

La fundamentación de los Derechos Fundamentales se hace extensiva al ámbito de las actividades laborales, las cuales forman parte de la totalidad socio-cultural y no un apartado de esta. Por lo tanto, desde la perspectiva socio-crítica de Marcuse, sólo el mejoramiento de las condiciones de los trabajadores, no representa en modo alguno un favorecimiento de la praxis de los derechos humanos, pues al asumirse el trabajador como parte activa del entramado socio-cultural las líneas a seguir para la consolidación de un ideal humanista implica necesariamente la realización permanente y continua de la libertad.

A los señalamientos realizados por Marcuse, es pertinente sumar las propuestas que realiza Fromm (1985), las cuales se ven reflejadas en una de sus obras más emblemáticas: El Miedo a la Libertad. Con relación a la libertad como expresión fundamental del ser humano, el autor referido señala que se tiende a considerarla un problema que se reduce sólo a lograr grados cada vez superiores cuantitativamente con relación a los que se han alcanzado en el curso de la historia moderna, creyendo que es suficiente conservar esas conquistas frente a los poderes que se le oponen (pp. 136-137). Fromm considera que el problema no se reduce a lo cuantitativo y a las conquistas crecientes de libertad frente a los poderes externos. En ese sentido, señala lo siguiente:

Olvidamos que, aun cuando debemos defender con el máximo vigor cada una de las libertades obtenidas, el problema de que se trata no es solamente cuantitativo, sino también cualitativo; que no sólo debemos preservar y aumentar las libertades tradicionales, sino que, además, debemos lograr un nuevo tipo de libertad, capaz de permitirnos la realización plena de nuestro propio yo individual, de tener fe en él y en la vida (p. 137).

La importancia de una libertad interior, que se relaciona con el propio ser humano, con su yo individual y con el poder alcanzar la mayor creencia en sí mismo y en la vida, representa el planteamiento fundamental y de fondo que se encuentra presente en el aporte y fundamentación que hace Fromm a las tesis del Humanismo en el contexto de la realidad del mundo actual. 
Este planteamiento no debe, sin embargo, ser interpretado como una postura romántica dirigida a negar las conquistas que en el marco de la modernidad se ha alcanzado con respecto a este derecho humano fundamental como lo es el de la libertad. En Fromm existe y persiste un claro reconocimiento a la modernidad como etapa histórica donde el ser humano ha alcanzado innegables conquistas en materia de derechos humanos, sobre todo el que considera más esencial y determinante de todos: El derecho a la libertad.

En ese sentido, el planteamiento hacia una búsqueda de libertad interior e individual debe ser interpretado como un avance hacia el cual debe tender siempre el ser humano como expresión de un proceso de continuo perfeccionamiento individual y social con el cual la humanidad se enriquece cualitativa y cuantitativamente en cuanto a sus derechos se refiere. A ese respecto, Fromm señala lo siguiente:

La historia de la humanidad no sólo es un proceso de individuación creciente, sino también de creciente libertad. El anhelo de libertad no es una fuerza metafísica y no puede ser explicado en virtud del derecho natural; representa, por el contrario, la consecuencia necesaria del proceso de individuación y del crecimiento de la cultura. Los sistemas autoritarios no pueden suprimir las condiciones básicas que originan el anhelo de libertad; ni tampoco pueden destruir la búsqueda de libertad que surge de esas mismas condiciones (p. 314).

Respecto a lo planteado, el Humanismo presente en Fromm tiene un carácter claramente optimista del ser humano y de las posibilidades en la consolidación y perfeccionamiento de su derecho a la libertad, partiendo de una noción de progreso y evolución permanente de la cultura y de la humanidad, a pesar de la presencia y las acciones de los sistemas autoritarios y de las diferentes formas opresivas del poder económico, político y social.

La esencia de esta propuesta constituye un aporte de importancia significativa para reforzar los planteamientos relacionados con el $\mathrm{Hu}$ manismo en clave moderna y las posibilidades de éste como elemento clave para fortalecer la fundamentación de los Derechos Fundamentales en el marco de una realidad donde las consecuencias de la razón tecnológica ponen en tela de juicios la pertinencia y las posibilidades del pensamiento humanista y de la modernidad como vías que conducen a una realización permanente de los derechos humanos.

Al hacer el análisis y reflexión de los aspectos abordados por los autores antes referidos, se puede inferir, por una parte, la existencia de una severa crítica a la modernidad y los hechos que en el marco de la misma han impactado severamente a la humanidad; y por otra, 
un reconocimiento a los avances que en materia de las libertades y derechos humanos en general se han alcanzado en el marco de la misma. Igualmente, se destaca en los planteamientos revisados que la corriente Humanista pasa por las relaciones y acciones que el hombre lleva a cabo en el mundo, lo que implica una revisión de los conceptos de dicha corriente, a los fines de consolidar un ideal que se adecue y tenga sintonía con la realidad actual.

Uno de los planteamientos donde se inscriben las ideas orientadas hacia una crítica dirigida a forjar una nueva visión Humanista, se encuentra representado en lo que plantea Marban (2002), cuando afirma lo siguiente:

Es necesario llegar al fondo de las contradicciones internas de nuestra cultura, para que emerja, al menos como síntoma, la necesidad de una cultura nueva. Lo que define al hombre es el nosotros del hombre, la comunicación intersubjetiva, y en la dinámica de lo intersubjetivo del hombre, la comunicación desempeña un papel primordial. Es allí donde cobra sentido toda la acción humana (p. 21).

El Humanismo propuesto desde una visión crítica se corresponde con una relectura de las ideas tradicionales relacionadas con esta corriente, a los fines de adaptarlas a los cambios que se producen en el mundo, partiendo del reconocimiento de las grandes contradicciones existentes en la cultura occidental y poniendo en tela de juicio a la razón y al hombre como individuo, como ejes centrales de los cambios necesarios para el avance de la humanidad.

Con relación a lo que se señala en este planteamiento, es pertinente destacar lo que afirma Orella (2001), cuando expresa que en una perspectiva crítica y renovadora con relación al Humanismo se propone lo siguiente:

Parte de la premisa de cuestionar la realidad existente hasta ahora, y deja de representarse al hombre como el centro y la medida de todas las cosas. Ahora comienza a prevalecer la pluralidad y multiplicidad de la sociedad, que debe convivir en un marco de globalización económica más humanizada (p. 227).

En los aspectos señalados anteriormente, se propugna y reconoce la existencia de una diversidad, de una multiplicidad de culturas y etnias, que se encuentran conviviendo en un marco de globalización. En ese sentido, las posibilidades de supervivencia de la humanidad, se encuentran en la profundización en los cambios de modelos económicos centrados en una noción de progreso tecnológico, a modelos de producción basados en la sustentabilidad y sostenibilidad y donde se reconozca y respete la diversidad en todas sus formas de expresarse. 
Respecto a lo antes referido, el autor ya referido plantea que se hacen necesarias: «nuevas normas políticas y de convivencia social, así como ético-personales, al tiempo que se salvaguardan los derechos de los demás, y todo ello desde el altruismo, la estética, el sentimiento y la imaginación» (p. 252).

La preeminencia de la razón tecnológica y el hombre individual como eje central, no es pertinente con estos cambios, pues las bases de un Humanismo Contemporáneo dirigido a darle sustentación a los Derechos Fundamentales, no pueden estar sino «en la misma condición humana» (ibídem), entendiéndose ésta, como la humanidad con su carácter diverso, contradictorio, pero, a la vez, con la necesidad de orientarse a una razón intersubjetiva que prevalezca sobre la racionalidad tecnológica y sobre la razón individual.

Para complementar lo antes expuesto, Márquez (2003) afirma lo siguiente:

El paradigma racionalista de la modernidad capitalista nos ha llevado a la crisis y al caos de una forma de pensar y hacer la Historia que no debería ser más. Esto ha propiciado un cuestionamiento a la metafísica y un escepticismo epistémico acerca del poder constituyente de la razón en el logro de un mundo humano de libertad y progreso (p. 123).

En ese sentido, el planteamiento de fondo del Humanismo en clave contemporánea o neo-moderna, es de una profunda crítica de la razón instrumental como garantía del desarrollo y progreso integral del ser humano como tal, en virtud de su imposibilidad de alcanzar ese cometido. Esa imposibilidad, a pesar de contar con una base tecno-productiva suficiente, se debe al hecho que ha convertido el conocimiento científico en una estructura de poder político, estético, simbólico, comunicativo y educativo, entre otros, siempre al servicio de la dominación.

Tal situación dificulta la conformación de una base humanista que sirva de fundamento sólido a los Derechos Fundamentales, en el sentido de un real reconocimiento de las necesidades y requerimientos de la diversidad de culturas en esta materia, donde no prevalezcan los intereses de grupos económicos y políticos, sino los que provienen de la propia dinámica de dichas culturas.

A ese respecto, tiene pertinencia lo argumentado por Pérez Tapias (2006) al afirmar lo siguiente:

Del efectivo reconocimiento de los derechos humanos de todos, depende nuestra humanización, pues nada vale, es decir, naufraga 
toda pretensión de sentido, si no es desde las exigencias del reconocimiento de la dignidad ajena y propia en medio de nuestras múltiples relaciones (p. 163).

Con base a lo señalado, la configuración de un soporte humanista a los Derechos Fundamentales debe establecerse en los términos de un ir de la generalidad de los conceptos y principios y conceptos a la multiplicidad de las realidades de lo humano. Implica el reconocimiento de la diversidad humana, de cada individuo en singular, de cada grupo, de cada nación y de cada realidad cultural con sus características y definiciones propias, pues, tal como lo afirma Orejudo (2006) «los derechos humanos no son el patrimonio de los pensadores humanistas ni de los revolucionarios, sino de toda la humanidad» (p. 57).

En esa perspectiva, las críticas que se le hacen a la corriente Humanista, no implican necesariamente una negación absoluta de la misma, sino que se pueden entender como una reflexión a fondo de lo que ha significado el Humanismo en su versión modernista y la necesidad de generar cambios que apunten a la construcción de una alternativa humanista, desde la cual se incorporen los valores de la modernidad y no sus antivalores y donde, desde la perspectiva de lo que señala Fromm, se promueva una evolución permanente en las conquistas tanto cuantitativas como cualitativas de los derechos humanos.

Esta propuesta representaría, tal como lo señala Garagalza (2009) un "contrapunteo al ideal humanista vigente en la modernidad (y heredero de la tradición ontoteológica) que corta mediante la represión los vínculos del ser humano con el cuerpo, la materia, el eros, la naturaleza» (p. 189). Ello representaría la edificación de un Humanismo más humano, donde lo abstracto del hombre sea sustituido por su padecer, por su accionar y por su desenvolverse en el mundo social, histórico, político y económico.

La concreción del hombre en todas sus formas diversas, es decir como individuo, como ciudadano, como trabajador, como integrado a grupos; en fin, del hombre en sus creencias, pecados y virtudes, viene a ser lo que le da sentido a una visión humanista, que despojada de las abstracciones y generalizaciones generadas en la modernidad, pero enriquecida con las conquistas logradas, entre ellas los derechos del hombre, puede constituirse en un fundamento sólido, realista y en permanente proceso de florecimiento, de lo que representan los Derechos Fundamentales. 


\section{REFLEXIONES FINALES}

Los Derechos Fundamentales representan una de las expresiones más significativas surgidas de los avances que se han suscitado en la modernidad y constituyen una conquista que debe ser objeto de atención permanente, no sólo en cuanto el resaltar dicha conquista, sino también procurar su perfeccionamiento permanente tanto desde el punto de vista cualitativo como cuantitativo.

Dicho perfeccionamiento implica ir más allá de las proclamas y discursos, donde se resalta el significado de los mismos y la obligación de darle real cumplimiento en cuanto a su protección en los diferentes sociales y culturales. Ese perfeccionamiento tiene que ver más que todo, con una práctica que favorezca una concreción desde la cual se supere el carácter utópico que se le ha tratado de endilgar, como una forma de negar su pertinencia y factibilidad.

El planteamiento de fondo que se hace en la actualidad con relación a los Derechos Fundamentales consiste, entonces, en alcanzar el propósito de que los mismos sean alcanzados plenamente en el marco de la sociedad y ello requiere de un proceso de renovación e innovación que les permita acompañar la realidad de los diferentes contextos socioculturales y con relación a la forma como se ejercen las acciones dirigidas a garantizar su cumplimiento y promover su protección ante las diferentes formas del poder.

Valarino-Bracho (2003) afirma que «todo cumplimiento de los derechos humanos tiene que realizarse dentro del marco del producto general de la sociedad» (p. 134). En ese sentido, los derechos humanos deben alcanzar su concreción pasando de ser declaraciones universales puras a normas legales vigentes, que, a su vez, se expresen fácticamente a través de políticas concretas que apunten a ello.

El alcance de lo planteado implica un reto de elevada exigencia, aun cuando no imposible de alcanzar, que requiere conducir procesos a través de los cuales se le dé a los Derechos Fundamentales el carácter de factibilidad-viabilidad mediante el cual termine de superar la calificación de utópicos con que se ha tratado de tipificarlos y que tiene como trasfondo una visión anti-humanista en la cual se procura su sistemática negación, aduciendo su condición de ser «abstractos» ${ }^{6}$.

6 Esta posición ya ha sido referida en este artículo, atribuyéndose originariamente a Edmund Burke, quien, desde una visión enteramente conservadora niega los derechos humanos argumentando su carácter abstracto. La misma ha incidido en los planteamientos de filósofos como Heiddeger y Arendt y Foucault, entre otros. 
La revisión crítica de las ideas que de una manera u otra se relacionan y sustentan a los Derechos Fundamentales y la proposición de alternativas dirigidas a renovar y reforzar dichas ideas, constituye una de las acciones que se inscriben en el marco del reto antes señalado y las mismas se encuentran orientadas a fomentar un basamento teórico desde el cual estos derechos alcancen mayor concreción en atención a su pertinencia respecto a la cambiante dinámica social.

El desarrollo de este artículo ha tratado de apuntar hacia este cometido, en el sentido que en el mismo se ha desarrollado una descripción y análisis de los aportes y críticas a las propuestas del Humanismo como una de las corrientes en las cuales se le da fundamentación a los Derechos Fundamentales, destacando que dichos aportes y críticas representan elementos que permiten revisar estas propuestas y, a la vez, promover nuevas ideas y argumentos con los cuales se contribuya a la construcción de un basamento que, desde lo que se denominaría un Humanismo Contemporáneo, fortalezca la pertinencia y concreción de los Derechos Fundamentales.

Igualmente, en este estudio se ha desarrollado un análisis de uno de los planteamientos que surgen del antihumanismo y el antimodernismo, como el de Arendt, con la intención de demostrar que tales posturas vienen a constituir alertas e indicios de la necesidad de profundizar, por un lado, en la actualización de los fundamentos que desde el Humanismo se han planteado con relación a los Derechos Fundamentales y, por el otro, en formulación de las ideas $\mathrm{y}$ argumentaciones que permitan demostrar que tales derechos no representan nociones abstractas.

Este esfuerzo obedece, no sólo a la exigencia teórico-conceptual de darle una reactualización a los basamentos humanistas de los Derechos Fundamentales, sino también a la necesidad de que se alcance una verdadera y real humanización, la cual es posible en función de unos derechos debidamente fundamentados, en cuanto a su pertinencia y posibilidades.

A ese respecto, el autor de este artículo se hace partícipe de lo que señala Pérez Tapias:

Así, pues, entre la ideología y la utopía, en torno a los derechos humanos, que en su concreción histórica se ubican a su vez entre la moralidad y la legalidad, entre la idealidad ética y la facticidad política, se concentra la alternativa crucial de nuestro tiempo que, a pesar de sus riesgos retóricos, nos podemos permitir expresar -con Erich Fromm y parafraseando a Rosa Luxemburg- en los términos de humanismo o barbarie (p. 163). 
Las ideas vertidas en este artículo se orientan hacia la alternativa del Humanismo, que, aun con sus fallas y sus aspectos críticos, constituye una propuesta teórica desde la cual es posible darle permanente fundamentación a los Derechos Fundamentales y favorecer los procesos que conduzcan a su definitiva consecución.

\section{BIBLIOGRAFÍA}

ALEGRE, Antonio (2004). La Sofística y Sócrates: Ascenso y Caída de la Polis. Barcelona, España: Montesinos.

BULLOCK, Allan (2000). La Tradición Humanista en Occidente. Madrid: Alianza Editorial.

CHASTEL, André, y KLEIN, Robert. (2002). El Humanismo. Barcelona: Biblioteca General Salvat.

CHOZA, Jacinto (2009). «Heidegger y el Humanismo del siglo XXI». En: Amigo Fernández, María Luisa (Ed.). Humanismo para el siglo XXI: Propuestas para el Congreso Internacional "Humanismo para el siglo XXI». Bilbao: Universidad de Deusto.

ESTRADA, Juan (2009). «El Humanismo en el Siglo XXI». En: Amigo Fernández, María Luisa (Ed.). Humanismo para el siglo XXI: Propuestas para el Congreso Internacional "Humanismo para el siglo XXI». Bilbao: Universidad de Deusto.

FROMM, Erich (1985). El Miedo a la Libertad. Buenos Aires: Paidós. $338 \mathrm{pp}$.

GARAGALZA, Luis (2009). «Los humanismos tras los antihumanismos». En: Amigo Fernández, María Luisa (Ed.). Humanismo para el siglo XXI: Propuestas para el Congreso Internacional «Humanismo para el siglo XXI». Bilbao: Universidad de Deusto.

MARBAN, Joaquín (2002). "Hacia un nuevo Humanismo», en $\mathrm{Hu}$ manismo y Trabajo Social, $n .^{\circ} 1$. Escuela Universitaria de Trabajo Social de la Universidad de León.

MARCUSE, Herbert (1993). El hombre unidimensional. Barcelona: Planeta-De Agostini. 286 p.

MÁRQUEZ (2003). «Modernidad y Postmodernidad. Entre el Humanismo Histórico y la Razón Escéptica» en Ágora n. ${ }^{\circ}$ 1. Trujillo. Núcleo Rafael Rangel de la Universidad de los Andes (ULA). 
OREJUDO PEDROSA, Juan Carlos. «Defensa del humanismo y de los derechos humanos: la figura del sujeto y su historia». Eikasia. Revista de Filosofía. II. 7, p. 57 [Revista electrónica]. Disponible: http://www.revistadefilosofia.com/. pp. 43-58.

ORELLA, José Luis (2001). El Humanismo Postmoderno. Historia de los Humanismos. San Sebastián, España: Deusto.

PÉREZ TAPIAS, José Antonio. «Derechos Humanos y Ciudadanía Democrática: La responsabilidad moral por los derechos del otro». En: Herrrera Guido, Rosario (coord.) Hacia una nueva ética, México: Siglo XXI.

SARTRE, Jean Paul (2006). El Existencialismo es un Humanismo. México: Universidad Nacional Autónoma de México. Dirección General de Publicaciones y Fomento Editorial. Colección Pequeños Grandes Ensayos.

VALARINO-BRACHO, Carmen (2003). «Venezuela, Polarización Ideológica y Democracia». En Romero, Alexis, Sandoval, Andrés y Salazar, Robinson (Coord.). Venezuela: Horizonte democrático en el siglo XXI. Maracaibo, Venezuela: Sociedad Zuliana de Sociología. 